\title{
Computational Modeling of Metallurgical Furnaces
}

\author{
ALEXANDRA E. ANDERSON $\left(1,{ }^{1,5}\right.$ FISEHA TESFAYE, ${ }^{2}$ \\ CHUKWUNWIKE O. ILOEJE, ${ }^{3}$ and STUART NICOL ${ }^{4}$ \\ 1.-Gopher Resource, 6505 Jewel Ave, Tampa, FL, USA. 2.-Johan Gadolin Process Chemistry \\ Centre, Åbo Akademi University, Henrikinkatu 2, FI-20500 Turku, Finland. 3.-Energy Systems \\ Division, Argonne National Laboratory, 9700 South Cass Avenue, Lemont, Illinois 60439- \\ 6903, USA. 4.-Glencore Technology, 160 Ann St, Brisbane 4000, Australia. \\ 5.—e-mail: allieanderson0@gmail.com
}

Metallurgical furnaces are inherently complex, processing multi-component, muti-phase materials in high-temperature, hazardous environments. These conditions make it difficult to fully resolve the phenomena occurring within furnaces through observation and measurement alone. To advance toward the goal of more efficient and productive operations, furnace phenomena must be better understood to allow for directed optimization and improvement efforts. Given the dual constraints of physico-chemical complexity of furnace phenomena and the hazardous environments that make direct measurements challenging, there exists an unmet need for achieving this improved understanding. Computational modeling and simulation have the promise to meet this unmet need. Computational techniques have already aided in our understanding of metallurgical furnaces, and they continue to be developed and refined today.

This special topic details recent developments in computational modeling of metallurgical processes, with a focus on experimentally validated models and those that have been implemented to improve operations and/or design. The topic consists of 13 peer-reviewed articles, including a review article, all of which focus on the use of computational modeling for improving the operation of (1) metallurgical production furnaces, (2) refining vessels and (3) casting lines. Different types of computational models are utilized for these tasks. The primary models employed in this special topic include:

- Computational fluid dynamics (CFD)

- Discrete element method (DEM)

- Kinetic models based on an effective equilibrium zone approach (EEZA)

(Received January 27, 2022; accepted January 31, 2022; published online March 7, 2022)
- Thermodynamic and energy balance analysis

- Machine learning models

The first six articles in this special topic utilize CFD techniques to model metallurgical operations. In the paper, "CFD modeling of multiphase flow in an SKS furnace: the effect of tuyere diameter and bath depth," Song and Jokilaakso present a multi-fluid CFD model of a scaled-down ShuiKouShan (SKS) furnace used to process copper-bearing material. Their model is validated using a laboratory-scale water reactor and studies the impact of the tuyere diameter and bath depth on the flow patterns within the furnace bath. Based on the simulation results, the authors recommend ranges for both variables that would increase the agitation of the bath, thereby improving the reaction performance of the furnace.

Yang et al. also examine the impact of various parameters using a laboratory-scale furnace in their paper entitled "Numerical analysis of flash ironmaking process in a newly proposed counter-current downer" by developing a multi-phase CFD model of a downer for flash ironmaking technology (FIT). Both counter-current and co-current downer operations are simulated using a Eulerian-Lagrangian framework, in which the gas phase, the feed particles and the major iron oxide reduction reactions are all considered. The modeling effort produced numerous insights on methods to improve reduction efficiency and metal yield.

The article "Numerical study on gas-metal-slag interaction with single-flow postcombustion oxygen lance in the steelmaking process of a top-blown converter" by Dong et al. presents a simulation of an operational top-blown steel furnace using a CFD volume of fluid (VOF) framework. The authors compare the operation of two different styles of oxygen lances with the goal of maximizing mixing in the molten steel bath. The model shows 
improvements in furnace operation using a redesigned lance, the results of which were also validated through in-plant trials.

In the article "Blast furnace hydrogen injection: investigating impacts and feasibility with computational fluid dynamics," Okosun et al. detail a multifaceted CFD study on an iron blast furnace aimed at understanding the effects of replacing natural gas injection with hydrogen injection. The evaluation uses previously developed models for the tuyere blowpipes, raceways and furnace shafts, accounting for multi-phase components and the characteristic chemical reactions within the furnace. The modeling results show promising potential for the replacement of natural gas with hydrogen, although the authors note that further research will be required to fully understand how to successfully operate iron blast furnaces with hydrogen injection.

The study entitled "CFD modeling of the melting behavior of a fayalitic slag" by Obiso et al. develops a CFD model to simulate the melting and solidification of fayalitic slag, a common slag encountered in the processing of non-ferrous materials. The goal of the study was to determine a rate constant $\left(\mathrm{A}_{\text {mushy }}\right)$ for melting/solidification of the fayalitic slag through both experimental and numerical investigation. The authors noted that the development of phase change models in slags is necessary for more accurate simulations of metallurgical furnaces, especially those in which the formation of slag freeze linings significantly affects the thermal balance.

The last paper focused on metallurgical production furnaces is entitled "A review of computational capabilities and requirements in high-resolution simulation of nonferrous pyrometallurgical furnaces" by Anderson et al. and provides a comprehensive review on CFD modeling efforts of various types of furnaces employed in the aluminum, copper and lead industries. The paper summarizes recent studies organized by commodity and furnace type. The final section in the article outlines typical approaches used for multi-phase modeling of metallurgical furnaces and provides a commentary on future improvements in commercial codes that will be necessary to more accurately model whole-furnace phenomena.

The next set of articles focuses on the CFD modeling of refining vessels and casting operations. In the article "Numerical and physical modeling of liquid inclusion's behaviors in steel-slag two-phase system," Liu et al. describe both physical and numerical modeling studies on a steel refining process in which liquid inclusions were present in a mixture of molten steel and slag. The CFD model incorporates three liquid phases (slag, molten metal and liquid inclusions) and was validated using data generated from a physical model. The main conclusions drawn by the authors are that inclusion size, inclusion viscosity and interfacial tension between the molten steel and the inclusion all impact the speed at which inclusions float to the surface of the slag, providing actionable information for operational improvement.

Chen et al. present a study in their paper entitled "Effect of nonequilibrium decarburization on inclusion transfer during single snorkel $\mathrm{RH}$ vacuum refining" that also aims to employ CFD modeling to investigate methods to improve inclusion removal from molten steel. This paper focuses on the simulation of solid non-metallic inclusions in single snorkel Rheinstahl-Heraeus (SSRH) reactors.

$\mathrm{Li}$ et al. detail a study evaluating flow-induced erosion on the components within Kanbara refining reactors in the article entitled "Computational evaluation of flow-induced abrasion of blade and ladle in Kanbara reactors for hot metal desulfurization." The numerical model examines the impact of three different parameters: blade dimensions, impeller immersion depth and impeller rotational speed. The results were used to minimize component abrasion in the design of an operational reactor.

The final CFD paper in this special topic, "A new method to reduce the shielding effect of copper mold in the bloom continuous casting with M-EMS" by Jiang and Zhang simulates a continuous steel casting operation utilizing electromagnetic stirring within copper molds. The authors note that copper molds typically inhibit electromagnetic stirring; the model was used to design new insulating layers that would permit the use of electromagnetic stirring within the copper molds.

The last three articles employ computational methods other than CFD to examine the operation and design of metallurgical furnaces. In the article "Development of an electric arc furnace simulation Model using the effective equilibrium reaction sone (EERZ) approach" by Van Ende et al., a kinetic model based on the EERZ approach is developed for an EAF. The model is constructed using kinetic expressions and thermodynamic databases and can accurately predict outlet temperatures as well as slag and metal composition in an operational EAF. The authors conclude that the model is an effective tool for the optimization and redesign of furnace operations.

Nam et al. present a thermodynamic analysis of a ferromanganese submerged arc furnace in the paper entitled "Ferromanganese production in a submerged arc furnace: thermodynamic and energy balance analysis." The model is constructed using FactSage databases and includes inputs such as slag flux composition, quantity of coke additions and process temperature. The authors use the model to develop an improved slag fluxing strategy to increase manganese yield in the furnace.

The final paper in the topic, "Machine learning modeling of gas utilization rate in blast furnaces" by Jiang et al., studies an iron blast furnace gas utilization (GUR) rate with models based on muilt- 
layer perceptron (MLP) and extreme learning machine algorithms. The models are trained using plant data and are able to accurately predict GUR rates, which is information that can be used to improve furnace operations.

The peer-reviewed papers in this special topic will be of interest to the broad JOM readership, especially those looking to improve or develop computational models of various types of metallurgical operations. To download any of these papers, please follow the URL below https://ink.springer.com/jour nal/11837/74/4/page/ 1 to the table of contents webpage for the April 2022 issue (vol. 74, no. 4).

\section{ACKNOWLEDGMENTS}

Editors of this topic sincerely thank all authors and reviewers that have contributed to the success of this special issue. We are convinced that your expertise has resulted in an excellent JOM special topic. The authors are also grateful to the Academy of Finland (decision number 311537) and the CircVol 6Aika project for financial support as part of the activities of the Johan Gadolin Process Chemistry Centre at Åbo Akademi University.

\section{CONFLICT OF INTEREST}

On behalf of all authors, the corresponding author states that there are no conflicts of interest.

Publisher's Note Springer Nature remains neutral with regard to jurisdictional claims in published maps and institutional affiliations. 